\title{
Classification and mapping of rangeland vegetation physiognomic composition using Landsat Enhanced Thematic Mapper and IKONOS imagery
}

\author{
David Mfitumukiza $^{1}$, Ellen Kayendeke ${ }^{2}$, Mwanjalolo, J.G. Majaliwa ${ }^{3}$, \\ ${ }^{1}$ Makerere University Department of Geography, Geoinformatics and Climatic Sciences, P.O. Box \\ 7298, Kampala, Uganda. Email: dmfitumukiza@gmail.com \\ ${ }^{2}$ Makerere University Department of Environmental Management, 7098, Kampala, Uganda. \\ ${ }^{3}$ Makerere University Department of Geography, Geoinformatics and Climatic Sciences, P.O. Box \\ 7298, Kampala, Uganda.
}

\begin{abstract}
Despite the significant role of vegetation maps in understanding and monitoring patterns of rangeland ecosystems, limited work has been done in mapping rangeland vegetation especially in Africa. In this study, characterisation of vegetation composition and assessment of Landsat ETM+ and IKONOS spectral discrimination effectiveness for mapping rangeland physiognomic vegetation cover types using both maximum (ML) likelihood and fuzzy classifiers was done in Rakai and Kiruhura districts, South Western Uganda. Plot vegetation species growth form, cover and height data were collected from 450 sampling sites based on eight spectral strata generated using unsupervised image classification. Field data were grouped at four levels of seven, six, three and two vegetation physiognomic classes which were subjected to both ML and fuzzy classification using both Landsat ETM+ and IKONOS. Results of mapping accuracy assessment showed that IKONOS imagery classification was more accurate than Landsat ETM+. Fuzzy classification was associated with significantly higher mapping accuracy than $M L(p<0.01)$. The highest overall accuracy with ML was $62.8 \%$ and $76.2 \%$ for Landsat ETM+ and IKONOS compared to $66.4 \%$ and $81 \%$ respectively when using fuzzy classification. Vegetation composition in the study area was shifting from woody to herbaceous dominated cover with predominance of stress resistance grass species. Improvement in mapping accuracy when using fuzzy classifier in this study provides useful insights in the limitations of maximum likelihood. There is need to investigate other classifiers in order to improve rangeland vegetation mapping and monitoring.
\end{abstract}

\section{DOI: http://dx.doi.org/10.4314/sajg.v3i3.1}

\section{Introduction}

Mapping the distribution of vegetation cover types is important for determining the patterns of variability and change of rangeland forage (Vicente-Serrano et al., 2006). Vegetation maps are used as a basis for planning, implementing and analyzing the results of subsequent rangeland inventory activities and perusal of the maps themselves often provides insights into broad environmental patterns and ecological relationships (Herlocker, 1999, Boelman et al., 2005). Despite the significant role that vegetation cover information plays in monitoring, no or limited work has been done in mapping rangeland vegetation especially in Africa. There is need for regular rangeland 
vegetation monitoring to provide up-to-date information on vegetation cover for grazing management purposes (Mueller-Dombois and Ellenberg, 1974, Gordon, 2009).

Satellite remote sensing from space is the best method for regularly updating maps of the rangeland vegetation cover (Chopping, et al., 2006). It allows for a quick, cost effective and systematic way of obtaining uniform and up-to-date information (Beeri et al., 2007, Moreau, 2003, Booth and Tueller, 2003). Studies have revealed that use of remote sensing has improved environmental analysis by providing a means to expand their temporal and spatial scales (Booth and Tueller, 2003, Turner, 2003). Attempts in vegetation mapping have been conducted using midresolution satellite imagery especially Landsat (Trodd and Dougill, 1998). Moreover these mapping efforts have been centred on general land cover mapping (NBS, 1992, Otukei and Blaschke, 2010) and not vegetation cover structure, which is essential for quantifying pastureland productivity (UWA, 2003). Vegetation mapping that will detect ecologically important variations in structure and composition over extensive rangelands with acceptable error rates is essential for rangeland management (Booth and Tueller, 2003). There have been no comprehensive rangeland vegetation mapping for Uganda using satellite imagery and as such, there is lack of knowledge regarding the use of spectral discrimination of the vegetation classes unique to Ugandan rangelands.

The costs of high resolution imagery like IKONOS pose a financial challenge (Booth and Tueller, 2003) especially for the developing world. However, their advantage over medium resolution of providing high quality imagery needs to be explored for improved vegetation mapping. There is also need to test and establish the best classification techniques for rangeland vegetation mapping. Rangeland vegetation in East Africa is characterised by a recurring pattern of small vegetation patches (Pratt and Gwynne, 1977, Bloesch, 2002) that make it difficult to have entirely homogenous image pixels even with very high resolution imagery. The specific design of fuzzy classification is potentially useful in solving such mapping problems associated with mixed pixels (Lillesand et al., 2004, Jensen, 1996). Therefore there is need to exploit the potential provided by this classifier for obtaining reliable information on rangeland vegetation.

The study is an attempt to explore the possibilities of quick, systematic and cost effective rangeland vegetation mapping procedures that maximize physiognomic classification accuracy. The physiognomic classification considered here, consists of description and measurement of the life form and appearance of the vegetation (Brower et al., 1997). The specific objective was to characterise vegetation composition and assess Landsat ETM+ and IKONOS spectral discrimination effectiveness for mapping vegetation physiognomic cover types using both maximum likelihood and fuzzy classifiers. The questions that this research attempted to answer were: What is the vegetation physiognomic and species composition? Can the rangeland vegetation physiognomic classification as documented by Pratt and Gwynne (1977) be effectively discriminated using Landsat ETM+ and IKONOS satellite images? Does fuzzy classification yield 
significantly higher accuracy results than maximum likelihood algorithm in rangeland vegetation physiognomic discrimination?

\section{Data and methods}

\subsection{Study area}

The study was carried out in predominantly pastoralist sub-counties of Kacheera and Nyakashashara in Rakai and Kiruhura districts respectively in south western Uganda (Figure 1). This area is part of the 'cattle corridor' of Uganda that is primarily used for grazing of both domestic and wild animals on native vegetation. The altitude ranges between 1200 to 1400 meters above sea level. The rainfall is bimodal with an annual mean of $948 \mathrm{~mm}$. Mean annual temperature is $22.9^{\circ} \mathrm{C}$. Vegetation cover is composed mainly of alternating patches of woodland and grassland.

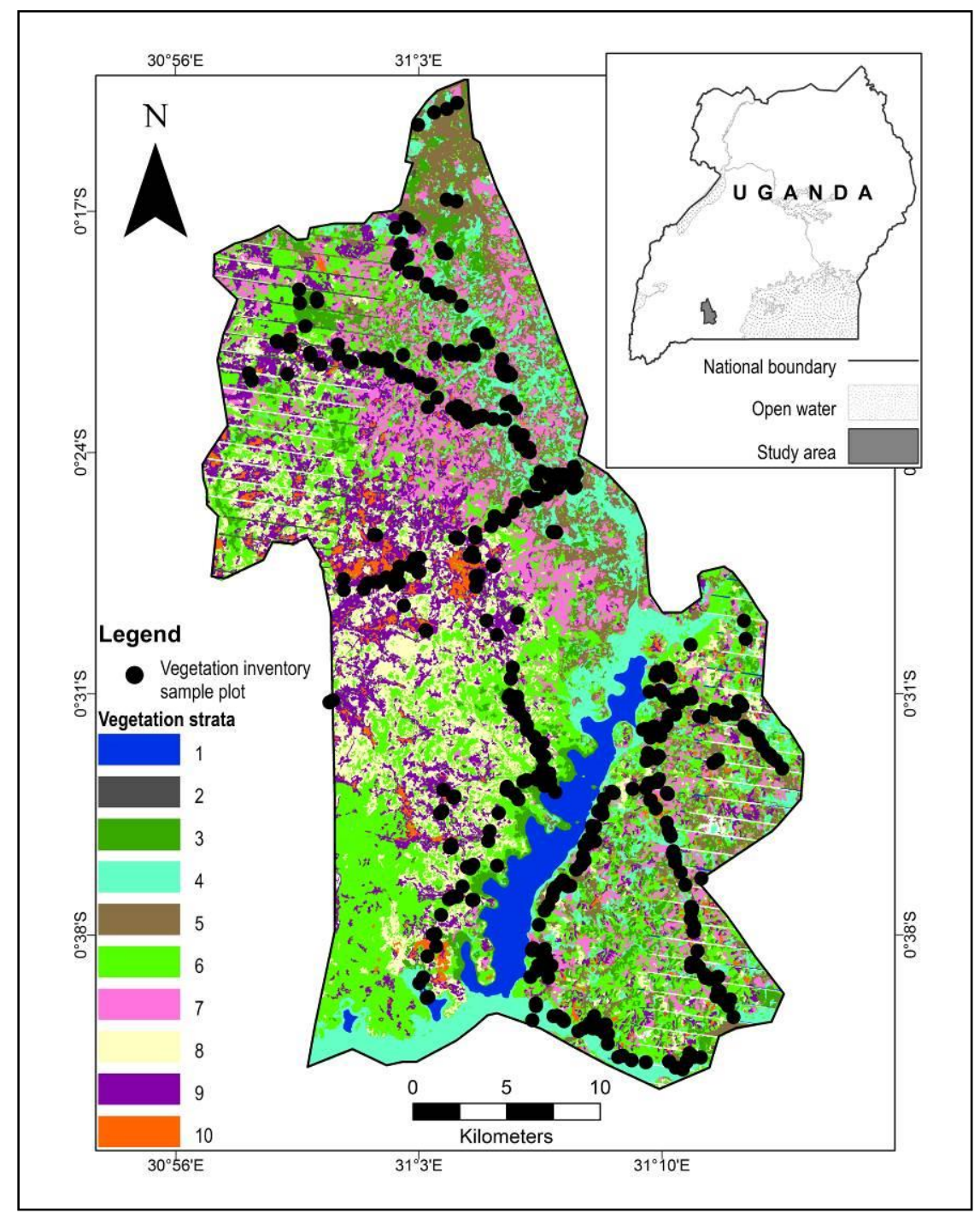

Figure 1. Location of study area in Uganda showing vegetation sampling strata and the distribution of sampling plots. Strata 1 (water surface) and 4 (wetlands) were not considered for sampling. The

hatches in the upper left corner are due stripes in the original to image used for stratification 


\subsection{Satellite imagery}

IKONOS imagery for June 2009 and Landsat Enhanced Thematic Mapper (ETM+) (Path/Row 185/60) for February 2008 were used. The images were orthorectified and georeferenced to WGS84, UTM Zone 36S. Landsat ETM+ and IKONOS images were obtained from the archives of United States Geological Surveys (USGS) and Satellite Imaging Corporation (SIC) respectively. Due to cost limitations, a small portion of IKONOS image approximately $75 \mathrm{Km}^{2}$ of the study area was used and it was not possible to obtain Landsat ETM+ and IKONOS images for the same season. The location of the portion of the IKONOS image was based on sufficient representation of all vegetation cover types in the whole study area. It was envisaged that use of images for different months would undermine the comparison of classification results. However, since both February and June we relatively dry and preceded by wet seasons, it was assumed that the effect of the difference on results would not be significant.

\subsection{Image and field sampling}

Based on experience from field reconnaissance and visual inspection of different combinations of 5, 4, 3 and 2 bands, a Landsat ETM+ image for February 2008 was stratified into 10 spectral patterns of cover classes (strata) using unsupervised classification in ERDAS IMAGINE 9.1 software. From eight of the resulting strata, a total of 450 sampling locations were selected with at least 50 in each of the strata. Most of the sampling locations were selected in the overlap area for Landsat ETM+ and IKONOS images. Two strata which corresponded with wetlands and water surfaces were not considered for sampling. All separately classified image strata of 60 x 60 meters (16 pixels) or greater were equally considered for sampling (Townshend, 1983). The location centre coordinates of the selected sites on the classified image were determined and entered into a Garmin 12 Global Positioning System (GPS) for navigation. From the sampling locations in the field, vegetation physiognomic composition (growth form: tree, shrub or herbaceous; cover; and height) data were collected following plot size recommendations by Kent and Coker (1994) for different vegetation cover types. Plots of 30 by $30 \mathrm{~m}, 15$ by $15 \mathrm{~m}$ and 2 by $2 \mathrm{~m}$ were used for tree, shrub and herbaceous (herbs and grass) cover respectively. Tree, shrub and herbaceous cover type definitions were based on Pratt and Gwynne (1977). To minimise time spent in the field, sampling sites were selected in areas which covered as many strata as possible to reduce travel distance between sampling points (Mueller-Dombois and Ellenberg, 1974). Field sampling focused on cover types that are used for grazing. Information on crop fields and settlement cover which were not considered during data collection was obtained from National Forestry Authority (NFA) of Uganda and integrated with data from the field.

Sampling locations (Figure 1) in the field as randomly selected from the image-derived strata were navigated to using GPS compass direction and distance. Where more than one vegetation cover types occurred, the grass/herb plot was nested into shrub plot, and shrub plot into tree plot. For each plot, individual plant species were identified and species percentage cover and height estimated and recorded. To ensure consistency in percentage cover estimates, the sampling team 
was trained together in the field as recommended by Kercher et al (2003). For each plot, location centre coordinates were recorded using a GPS.

\subsection{Field data processing}

Using the vegetation description by Pratt and Gwynne (1977), vegetation growth form (tree, shrub or herbaceous) cover and height data from field plots were grouped into physiognomic classes. The data were randomly divided into two datasets: one for classification training sample set and the other for accuracy assessment.

\subsection{Image classification}

An evaluation and comparison of the mapping results and their accuracies was done for both Maximum-likelihood (ML) and fuzzy classification based on physiognomic classes of the plot data using ERDAS IMAGINE 9.1 software. The steps for selection of training sites included assessment of statistical distribution of digital numbers of pixels around a given training site within the limits of the respective stratum for the various sampling points obtained using the plot sizes for the different vegetation cover types described under section 2.3 above. The patch sizes considered for training and test sampling plots of the different physiognomic classes were based on the minimum of 16 pixels (Townshend, 1983) to ensure consistency with the field data collection procedures. Pixel clusters considered to be mixed classes were avoided in training set selection. Comparison of the digital numbers with alternative sets of signatures of other sites with the same vegetation class was also done. The results of these steps served as the basis for subsequent selection of the best set to perform the classification.

\subsection{Accuracy assessment and classification improvement}

Using the accuracy assessment dataset, validation of the mapping results was done for the area covered by IKONOS for each type of remote sensing data. Confusion (error) matrices were constructed for classified vegetation maps and the testing dataset in ERDAS IMAGINE 9.1. Overall, producer's and user's accuracies were obtained from pixel matrices of classification results. This was done for the comparisons of mapping results between Landsat ETM+ and IKONOS images and between ML and fuzzy classification were tested using a t-test at a confidence interval of $95 \%$.

\section{Results}

\subsection{Vegetation physiognomic and species composition}

Vegetation species cover and height plot data resulted in seven physiognomic classes (bush grassland, bushland thicket, bushland, grassland, shrubland, woodland and wooded grassland) (Table 1). The vegetation cover was mainly constituted of $7.7 \%$ trees, $24.4 \%$ shrubs and $49.2 \%$ 
grasses. Other herbs were least dominant across all vegetation types with an average cover of 4.6\%. The average height for trees was $7.6 \mathrm{~m}, 2 \mathrm{~m}$ for shrubs and $20 \mathrm{~cm}$ for herbaceous layer.

Table 1. Vegetation cover, height and species composition

\begin{tabular}{|c|c|c|c|c|c|c|}
\hline \multirow[b]{2}{*}{ Vegetation type } & \multicolumn{2}{|c|}{ Woody } & \multicolumn{2}{|c|}{ Herbaceous } & \multicolumn{2}{|c|}{ Dominant species } \\
\hline & Cover $(\%)$ & Height (m) & Cover $(\%)$ & Height $(\mathrm{cm})$ & Woody & Herbaceous \\
\hline Bush grassland & 22 & $1-8$ & 66 & $3-45$ & $\begin{array}{l}\text { Acacia gerrardii } \\
\text { Acacia hockii }\end{array}$ & $\begin{array}{l}\text { Sporobolus pyramidalis } \\
\text { Brachiaria decumbens }\end{array}$ \\
\hline Bushland thicket & 51 & $2-14$ & 33 & $1-42$ & $\begin{array}{l}\text { Acacia hockii } \\
\text { Acacia sieberiana } \\
\text { Rhus natalensis }\end{array}$ & $\begin{array}{l}\text { Sporobolus pyramidalis } \\
\text { Brachiaria decumbens }\end{array}$ \\
\hline Bushland & 31 & $1-5$ & 54 & $5-53$ & $\begin{array}{l}\text { Carrisa edulis } \\
\text { Acacia hockii } \\
\text { Acacia gerrardii } \\
\text { Rhus natalensis }\end{array}$ & $\begin{array}{l}\text { Sporobolus pyramidalis } \\
\text { Brachiaria decumbens }\end{array}$ \\
\hline Grassland & 7 & $1-7$ & 68 & $5-100$ & $\begin{array}{l}\text { Lantana camara } \\
\text { Acacia hockii }\end{array}$ & $\begin{array}{l}\text { Cymbopogon nardus } \\
\text { Brachiaria decumbens } \\
\text { Loudetia kagerensis }\end{array}$ \\
\hline Shrubland & 36 & $2-6$ & 47 & $5-45$ & $\begin{array}{l}\text { Acacia gerrardii } \\
\text { Rhus natalensis }\end{array}$ & $\begin{array}{l}\text { Sporobolus pyramidalis } \\
\text { Brachiaria decumbens }\end{array}$ \\
\hline Woodland & 51 & $2-8$ & 33 & $4-23$ & $\begin{array}{l}\text { Acacia hockii } \\
\text { Acacia gerrardii } \\
\text { Rhus natalensis }\end{array}$ & $\begin{array}{l}\text { Setaria homonyma } \\
\text { Brachiaria decumbens }\end{array}$ \\
\hline Wooded grassland & 24 & $3-11$ & 67 & $4-85$ & $\begin{array}{l}\text { Acacia hockii } \\
\text { Acacia gerrardii } \\
\text { Rhus natalensis }\end{array}$ & $\begin{array}{l}\text { Sporobolus pyramidalis } \\
\text { Brachiaria decumbens }\end{array}$ \\
\hline
\end{tabular}

\subsection{Image classification and accuracy assessment}

Using all the seven physiognomic classes from field vegetation data the overall accuracy with Landsat ETM+ was $17.6 \%$ and $23 \%$ for ML and fuzzy classification respectively. The overall classification accuracy for IKONOS was $23.8 \%$ and $33 \%$ with ML and fuzzy classification respectively. With such unsatisfactory results, an attempt was made to merge the seven classes at different levels through an iterative classification process to evaluate whether merged classes would result in better accuracy of vegetation mapping. Merging was based on the nature of overlap in the class definitions as reflected in the field data and classification results of the original seven classes. The resulting three levels of vegetation class merging were: six classes (Grassland, Bushland, Bushland thicket, Shrubland, Wooded grassland, Woodland); three (Grassland, Bushland, Woodland); and two classes (Grassland, Woodland) (Table 2). Each of these three vegetation physiognomic class grouping levels was also subjected to ML and fuzzy classification using both Landsat ETM+ and IKONOS imagery. The last level (two classes) was as a result of grouping all woody vegetation dominated classes into a woodland class and those dominated by grass cover into a grassland class. 
Table 2. Summary of the vegetation classes merging levels with overall accuracy (\%) assessment of Landsat ETM+ and IKONOS imagery classification using maximum likelihood (ML) and fuzzy classifiers

\begin{tabular}{|c|c|c|c|c|c|c|}
\hline \multirow[b]{2}{*}{$\begin{array}{l}\text { Classification } \\
\text { Level (Classes) }\end{array}$} & \multirow[b]{2}{*}{ Merged Classes (New Name) } & \multirow[b]{2}{*}{ Classes } & \multicolumn{2}{|c|}{ Landsat ETM+ } & \multicolumn{2}{|c|}{ IKONOS } \\
\hline & & & ML & Fuzzy & ML & Fuzzy \\
\hline $\begin{array}{l}\text { Level } 1 \text { (All } 7 \\
\text { classes) }\end{array}$ & No merging done & $\begin{array}{l}\text { Grassland, Bush grassland, } \\
\text { Bushland, Bushland thicket, } \\
\text { Shrubland Wooded } \\
\text { grassland, Woodland }\end{array}$ & 17.6 & 23.1 & 23.8 & 33.0 \\
\hline $\begin{array}{l}\text { Level } 2 \text { (6 } \\
\text { classes) }\end{array}$ & $\begin{array}{l}\text { Grassland + Bush grassland } \\
\text { (Grassland) }\end{array}$ & $\begin{array}{l}\text { Grassland, Bushland, } \\
\text { Bushland thicket, } \\
\text { Shrubland, Wooded } \\
\text { grassland, Woodland }\end{array}$ & 28.6 & 33 & 40.7 & 41.7 \\
\hline $\begin{array}{l}\text { Level } 3 \text { ( } 3 \\
\text { classes) }\end{array}$ & $\begin{array}{l}\text { Grassland + Bush grassland + } \\
\text { Wooded grassland (Grassland) } \\
\text { Bushland + Shrubland + } \\
\text { Bushland thicket (Bushland) }\end{array}$ & $\begin{array}{l}\text { Grassland, Bushland, } \\
\text { Woodland }\end{array}$ & 57.1 & 61.5 & 61.5 & 62.0 \\
\hline $\begin{array}{l}\text { Level } 4(2 \\
\text { classes) }\end{array}$ & $\begin{array}{l}\text { Grassland + Bush grassland }+ \\
\text { Wooded grassland (Grassland) } \\
\text { Bushland + Shrubland }+ \\
\text { Bushland thicket + Woodland } \\
\text { (Woodland) }\end{array}$ & Grassland, Woodland & 62.6 & 66.4 & 76.2 & 81.0 \\
\hline
\end{tabular}

\section{Classification Comparisons}

Generally, merging classes resulted in improvement of classification accuracy for both ML and Fuzzy classification (Table 2). The last level of merger with two classes (woodland and grassland) (Figure 2) ML classification resulted in an overall accuracy of $62.6 \%$ for Landsat ETM+ and 76.2\% for IKONOS (Table 2). Fuzzy classification yielded better results than ML for both Landsat ETM+ and IKONOS. The overall accuracy for fuzzy based classification at this level was $66.4 \%$ using Landsat ETM+ while for IKONOS it was $81 \%$. Classification of IKONOS using ML into these two broader classes resulted in higher producer's accuracy than Landsat ETM+ for both woodland and grassland (Table 3). Similarly, IKONOS registered a higher user's accuracy for woodlands than Landsat ETM+, but the grassland user's accuracy (81.1\%) for Landsat ETM+ was higher than that from IKONOS classification (70\%).

All comparisons of ML and Fuzzy within and between IKONOS and Landsat ETM+ images did not result in any significant differences (Table 4). Whereas IKONOS was generally associated with higher classification accuracy, it was not statistically higher than for Landsat ETM+ $(\mathrm{p}=0.4)$. Overall the results of fuzzy classification were significantly better than those from ML algorithm $(\mathrm{p}=0.005)$. 


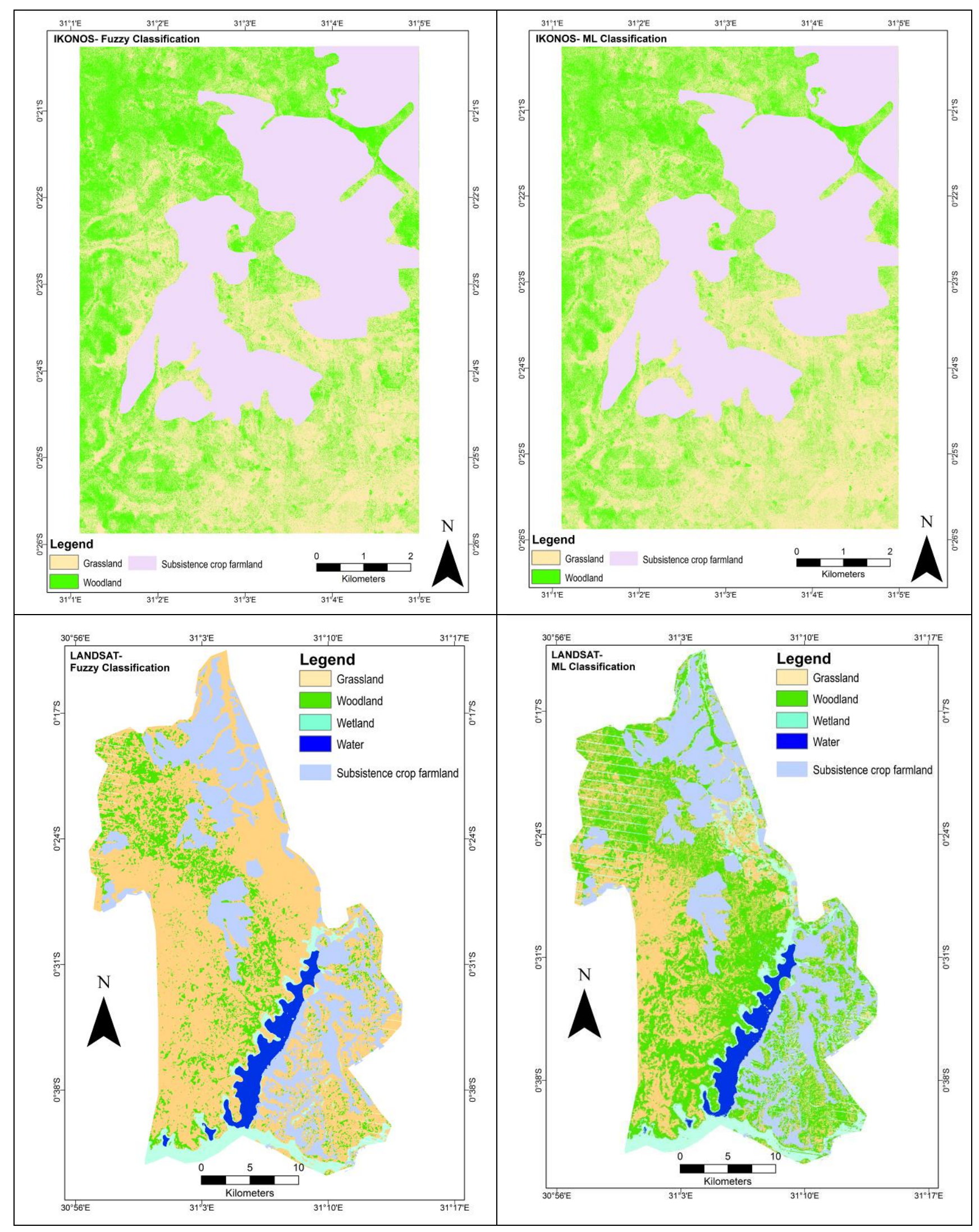

Figure 2. Vegetation classification maps from IKONOS and Landsat ETM+ imagery using maximum likelihood and fuzzy respectively 
Table 3. Maximum likelihood and fuzzy classification user's and producer's accuracy results based on two classes for both Landsat ETM+ and IKONOS images

\begin{tabular}{ccccccccc}
\hline & \multicolumn{3}{c}{ Landsat ETM+ } & \multicolumn{4}{c}{ IKONOS } \\
\hline & \multicolumn{2}{c}{$\begin{array}{c}\text { Producer's } \\
\text { Accuracy }(\%)\end{array}$} & \multicolumn{2}{c}{$\begin{array}{c}\text { User's Accuracy } \\
(\%)\end{array}$} & $\begin{array}{c}\text { Producer's Accuracy } \\
(\%)\end{array}$ & \multicolumn{2}{c}{$\begin{array}{c}\text { User's Accuracy } \\
(\%)\end{array}$} \\
\hline Class Name & ML & Fuzzy & ML & Fuzzy & ML & Fuzzy & ML & Fuzzy \\
\hline Grassland & 62.5 & 72.6 & 81.1 & 84.0 & 77.8 & 67.3 & 70.0 & 86.0 \\
Woodland & 62.8 & 78.2 & 64.3 & 73.8 & 75.0 & 92.1 & 81.3 & 79.1 \\
\hline
\end{tabular}

Table 4. Fuzzy and ML overall classification accuracy comparisons within and between IKONOS and Landsat ETM+ images

\begin{tabular}{ll}
\hline Comparison & $\mathbf{p}<\mathbf{0 . 0 5}$ \\
\hline ML and Fuzzy for Landsat ETM+ & $\mathrm{p}>0.05$ \\
ML and Fuzzy for IKONOS & $\mathrm{p}>0.05$ \\
ML Landsat ETM+ and ML IKONOS & $\mathrm{p}>0.05$ \\
Fuzzy Landsat ETM+ Fuzzy IKONOS & $\mathrm{p}>0.05$ \\
Over all IKONOS and Landsat ETM+ & $\mathrm{p}>0.05$ \\
Overall ML and Fuzzy & 0.0047 \\
\hline
\end{tabular}

\section{Discussion}

\subsection{Vegetation physiognomic and species composition}

Results of plant species composition in the study are indicated to be similar to those reported by Pratt and Gwynne (1977). However, grass species composition was found to be dominated by Brachiaria species and Sporobolus species as opposed to the dominance of Hyperrhenia species and Themeda species that was reported by Langdale-Brown (1970). This change in grass species dominance is probably due to the effect of increased grazing pressure (Purseglove, 1988). The dominance of $S$. pyramidalis is due to its fibrous nature that is normally detested by grazers. $S$. pyramidalis is also very resilient to disturbances like trampling, seasonal flooding, and excessive drought and burning (Phillips et al., 2003).

The vegetation growth form composition in the study area was dominated by herbaceous vegetation cover. This is differs from the findings reported by Pratt and Gwynne (1977) which indicated that the area was predominantly covered by woody vegetation. The most probable explanation to the difference is the current loss of woody vegetation as a result of cutting trees for charcoal especially Acacia sp (personal observation). Shrub cover in the area has reduced because of land clearing to increase the amount of herbage available for cattle grazing (UWA, 2003). Frequent fires have most likely also kept rangeland vegetation open by suppressing woody vegetation while favouring the growth of grasses and herbs (Herlocker, 1999, Osborne, 2000). The vegetation shifts could be attributed to increase in land under cultivation compared to what was reported by Pratt and Gwynne (1977). This can be explained by the increasing number of recent immigrants in the area whose livelihoods are crop farming dependant. Moreover the pastoralists are also currently more involved in growing food crops especially around their homesteads compared 
to the 1970s. The changes are indications of increasing population pressure on the rangeland which is usually associated with overgrazing, land degradation and loss of biodiversity (Gordon, 2009).

\subsection{Image classification and accuracy assessment}

Classification of Landsat ETM+ imagery resulted in a relatively lower accuracy compared to IKONOS when using the seven vegetation physiognomic classes. With a lower spatial resolution, discrimination of the vegetation classes when using Landsat ETM+ ought to have been more affected by mixed pixels than IKONOS. This trend is related to the findings by Phinn et al. (1996) in which they reported the importance of using high resolution imagery in improving biomass mapping accuracy in an environment characterised by spatial heterogeneity. Vegetation cover types in the study area occurred in a recurring pattern of small patches that may hardly be sharply defined within a Landsat ETM+ pixel of $30 \times 30 \mathrm{~m}$. Inevitably, this leads to many mixed pixels within vegetation classes. In their findings, Chopping et al. (2008) demonstrated that in cases of favourable relationships between pixel size and vegetation patch size, the use of higher resolution considerably improved classification accuracy. Whereas Landsat ETM+ has been reported to be a good tool for mapping vegetation (Cingolani et al., 2004), the level of detail presented by the physiognomic classes used was most likely higher than could be detected by the sensor as separate units. For example, it would probably be difficult to capture differences in same size canopies of Acacia shrubs which go up to six meters in a shrubland and Acacia trees in bushland which may range between 1 and 10 meters as described in the classification used here. The accuracy registered by IKONOS when using seven classes was also still very low with an overall improvement of 3.5\% only. Therefore the inaccuracies in classification were beyond the spatial resolution limitations of Landsat ETM+ and advantages of IKONOS. Results from merging of the seven classes at different levels confirmed that the most plausible explanation for this is the inadequate level of definition of the vegetation classes that could not be well discerned by both satellite sensors.

Merging of classes significantly increased mapping accuracy for both Landsat ETM+ and IKONOS. A related trend in accuracy improvement due to lowering of number of classification strata was reported by Schmidt (2003). However, even mapping at the second level of six vegetation classes, the accuracy was below $50 \%$ for both Landsat ETM+ and IKONOS images. On the other hand, when the six classes were merged to three, the accuracy increased by $28 \%$ for Landsat ETM+ and 20\% with IKONOS. Woodland at this level of classification could not be discriminated from the other two classes (grassland and shrubland). This was most probably due to overlapping spectral characteristics especially between woodland and shrubland whose species composition were in both cases dominated by Acacia species. The differences were only in growth form and height. Moreover, at this level, even the grassland class had woody species included from the original classes (bush grassland and wooded grassland) that potentially have similar spectral characteristics. 
There was a further considerable improvement in accuracy when mapping two vegetation (grassland and woodland) classes by $6 \%$ and $14 \%$ when using Landsat ETM+ and IKONOS respectively. This trend of results is a further indication that merging of vegetation classes reduces the effect of patchiness on classification. These results are related to the findings by Cherrill et al. (1994) in which they found out that definition of fewer vegetation classes resulted in more meaningful information units to the Landsat ETM+ recorded data hence improved accuracy. Besides, the patterns of reflectance spectra characteristic of grass dominated herbaceous layer are different than those of woody vegetation hence making it much easier to discriminate and map them with a relative higher accuracy. The presence of some patches of woody vegetation merged in grassland dominated class was still the most probable explanation to the inaccuracies at this level. Similarly, Chopping et al. (2006) reported that the occurrence of shrubs in both grassland and woody vegetation makes it difficult to map them as separate classes using satellite images.

\subsection{Classification comparisons}

When using fuzzy classification, significantly higher accuracy was realised compared to ML. The overall accuracy improved from $63 \%$ to $66 \%$ and from $76 \%$ to $81 \%$ with Landsat ETM+ and IKONOS respectively. These results are of the same magnitude as those in a study by Aynekulu et al. (2008) in which they reported an overall accuracy of $80 \%$ using a comparable number of land use/cover classes in Ethiopian rangelands. The improvement in accuracy when using fuzzy classification conformed to assertion that remotely sensed data are imprecise with fuzzy boundaries between different vegetation cover types which in turn are heterogeneous within the boundaries (Jensen, 1996). A hard classifier like ML which requires precisely defined set boundaries for which a given pixel is either a member of class or not would most likely result in a relatively lower accuracy compared to a fuzzy based classification.

\section{Conclusions}

Results have shown that rangeland vegetation cover in the study area is experiencing changes in species cover and composition with shift from woody to herbaceous dominated. Species dominance is drifting from more desirable to less desirable for grazing. This situation poses a need to optimise rangeland productivity for sustainable livelihoods and biodiversity conservation. This calls for proactive remedies such as regulated woody cover cutting and awareness rising on the importance of trees and shrubs in grazing land management.

Only two broad classes of physiognomic vegetation cover types were accurately mapped using fuzzy and ML from Landsat ETM+ and IKONOS images. Overall the findings of this study indicate that IKONOS reflectance spectra discriminate rangeland physiognomic vegetation classes better than Landsat ETM+ imagery. It is also shown that fuzzy classification resulted in higher 
discrimination ability of the physiognomic vegetation types than maximum likelihood. Better accuracy when using fuzzy classifier in this study provides useful insights in the limitations of maximum likelihood and need to investigate other classifiers in order to improve rangeland vegetation mapping. There is need to develop classification schemes for systematically defining rangeland vegetation classes that can realistically be discriminated by various levels of sensors. Future vegetation class definitions should aim at drawing clear boundaries among trees, shrubs and herbaceous growth forms to ensure reliable rangeland ecological and productivity assessments.

\section{Acknowledgments}

We would like to thank our field assistants Sarah Tumuhairwe, Nsiimire Peter and Gershome Arituha. This study was sponsored by Rockefeller foundation (Grant \# 2006 AR 016).

\section{References}

Archibald, S. 2008. African grazing lawns-How fire, rainfall, and grazer numbers interact to affect grass community states. Wildlife Management, 72, 492 - 501.

Aynekulu, E., Kassawmar, T. \& Tameme, L. 2008. Applicability of ASTER imagery in mapping land use/cover as a basis for biodiversity studies in drylands of norhern Ethiopia. African Journal of Ecology, 46, 19 - 23.

Beeri, O., Phillips, R., Hendrickson, J., Frank, A. B. \& Kronberg, S. 2007. Estimating forage quantity and quality using aerial hyperspectral imagery for northern mixed-grass prairie. Remote Sensing of Environment, 110, 216 - 225.

Bloesch, U. 2002. The dynamics of thicket clumps in the Kagera savanna landscape, East Africa. $\mathrm{PhD}$, Swiss Federal Institute of Technology Zurich (ETH). Shaker, Aachen, DE.

Boelman, N. T., Stieglitz, M., Griffin, K. L. \& Shaver, G. R. 2005. Inter-annual variability of NDVI in response to long-term warming and fertilization in wet sedge and tussock tundra. Oecologia, 143, 588 - 597.

Booth, D. T. \& Tueller, P. T. 2003. Rangeland monitoring using remote sensing. Arid Land Research and Management, 17, 455 - 467.

Brower, J. E., Zar, J. H. \& Von ende, C. N. 1997. Field and laboratory methods for general ecology, Michael D. Lange.

Cherrill, A. J., Lane, A. \& Fuller, R. M. 1994. The use of classified 5 Thematic Mapper imagery in characterisation of landscape composition: A case study in northern England. Journal of Environmental management, 40, 357 - 377.

Chopping, M., Su, L., Rango, A., Martonchik, J. V., Peters, D. P. C. \& Laliberte, A. 2008. Remote sensing of woody shrub cover in desert grasslands using MISR with a geometric-optical canopy reflectance model. Remote Sensing of Environment, 112, 19-34.

Chopping, M. J., SU, L., rango, A., Martonchik, J. V., Peters, D. P. C. \& Laliberte, A. 2006. Remote sensing of woody shrub cover in desert grasslands using MISR with a geometric-optical canopy reflectance model. Remote Sensing of Environment, 112, 19 - 34.

Cingolani, A. M., Renison, D., Zak, M. R. \& Cabido, M. R. 2004. Mapping vegetation in a heterogeneous mountain rangeland using landsat data: an alternative method to define and classify land-cover units. Remote Sensing of Environment, 92, 84-97.

Gordon, I. J. 2009. What is the Future for Wild, Large Herbivores in Human-Modified Agricultural Landscapes? Wildlife Biology, 15, 1-9. 
Herlocker, D. J. 1999. Rangeland ecology and resource development in eastern Africa, Nairobi, German Agency for Technical Co-operation.

Homewood, K. \& Brocking, D. 1999. Biodiversity, conservation and development in Mkomazi Game Reserve, Tanzania. Global Ecol. Biogeogr., 8, 301 - 313.

Homewood, K. M. 2004. Policy, environment and development in African rangelands. Environmental Science and Policy, 7, 125 - 143.

Jensen, J. R. 1996. Introduction to digital image processing New Jersey, Prentice-Hall, Inc.

Kent, M. \& Coker, P. 1994. Vegetaion description and analysis: A practical approach, London, Belhaven Press.

Kercher, S. M., Frieswyk, C. B. \& Zedler, J. B. 2003. Effects of sampling teams and estimation methods on the assessment of plant cover. Journal of Vegetation Science, 14, 899 - 906.

Langdale-Brown, I. 1970. Vegetation. In: Jameson, J. D. (ed.) Agriculture in Uganda. Second ed. London: Oxford University Press.

Lillesand, T. M., Kiefer, R. W. \& Chipman, J. W. 2004. Remote sensing and image interpretation, New York, John Wiley \& Sons Inc.

McNeely, J. A., Gadgil, M., Leveque, C., Padoch, C. \& Redford, K. 1995. Human influence on biodiversity. In: Heywood, V. H. (ed.) Global biodiversity assessment. Cambridge: United Nations Environment Programme (UNEP).

Moreau, S., Bosseno, R., GU, X. F., Baret, F. 2003. Assessing the biomass of Andean bofedal and totora high-protein wetland grasses from NOA/AVHRR. Remote sensing of Environment, 85, 516-529.

Mueller-Dombos, D. \& Ellenberg, H. 1974. Aims and methods of vegetation Ecology, Toronto, John Wiley $\&$ Sons, Inc.

NBS 1992. Technical report, National Biomass Study, Phase I. Kampala, Uganda: Forest department.

OSBORNE, P. L. 2000. Tropical ecosystems and ecological concepts, Cambridge, Cambridge University Press.

Otukei, J. R. \& Blaschke, T. 2010. Land cover changes assessment using decision trees, support vector machines and maximum likelihood classification algorithms. International Journal of Applied Earth Observation and Geoinformation, 12S, S27 - S31.

Phillips, S., Namaganda, M. \& Lye, K. A. 2003. 115 Ugandan grasses, Kampala, Makerere University Herbarium.

Phinn, S., Franklin, J., Hope, A., Stow, D. \& Huenneke, L. 1996. Biomass distribution mapping using airborne digital video imagery and spatial statistics in a semi-arid environment. Journal of Environmental management, 47, 139 - 164.

Pratt, D. J. \& Gwynne, M. D. 1977. Rangeland management and ecology in East Africa, Huntington, New York, Robert E. Krieger Publishing Co., Inc.

Purseglove, J. W. 1988. Tropical crops, Essex, Longman Group Ltd.

Schmidt, K. S. 2003. Hyperspectral remote sensing of vegetation species distribution in a saltmarsh, Enschede, ITC.

Townshend. Effects of spatial resolution on the classification of land cover type. In: FULLER, R. M., ed. Ecological Mapping from Ground, Air and Space, 1983 ITE, Monks Wood Experimental Station, Abbots Ripton, Huntingdon. Institute of Terrestrial Ecology, 101 - 112.

Trodd, N. M. \& Dougill, A. J. 1998. Monitoring vegetation dynamics in semi-arid African rangelands: Use and limitations of Earth observation data to characterize vegetation structure. Applied Geography, 18, 315-330.

Turner, M. D. 2003. Methodological reflections on the use of remote sensing and geographic information science in human ecological research. Human Ecol, 31, 255-279.

UWA 2003. Lake Mburo conservation area general management plan. Kampala: Uganda Wildlife Authority.

Vicente-Serrano, S. M., Cuadrat, J. M. \& Romo, A. 2006. Aridity influence on vegetation patterns patterns in the middle Ebro valley (Spain): Evaluation by means of AVHRR images and climate interoration techniques. Journal of Arid Environments, 66, 353 - 375. 